Open Access Full Text Article

\title{
Analysis of the Key Factors Affecting the Future of Medical Education Discipline in 2025 Based on STEPV Model: A Qualitative Study
}

This article was published in the following Dove Press journal:

Advances in Medical Education and Practice

\author{
Atiye Faghihi (D' \\ Mohammad Hoseini \\ Moghadam (1D) \\ Nikoo Yamani (D) \\ 'Department of Medical Education, \\ Medical Education Research Center, \\ Isfahan University of Medical Sciences, \\ Isfahan, Iran; ${ }^{2}$ Foresight Department, \\ Institute for Social and Cultural Studies \\ (ISCS), Tehran, Iran
}

Background and Objectives: Increasing developments in medical education have highlighted the role of medical education discipline in keeping with these developments. On the other hand, this discipline has been encountered with trends, events and challenges at national and international levels; so, there are concerns about its future. This study aimed to identify key factors affecting the future of the discipline from the viewpoint of stakeholders.

Materials and Methods: This study used a qualitative approach based on constructivist paradigm and was conducted in 2019-2018. Thirty-one participants (teachers, students and graduates) of medical education discipline from 8 universities of medical sciences in Iran were selected through purposive sampling with maximum diversity. Data were collected through semi-structured interviews and analyzed using directed content analysis.

Results: The key factors were classified into five main categories: social (characteristics of entrants into the discipline, motivations of candidates for entry into the discipline, national and international communications and interactions, the status of medical education within the academic community, and movement toward social accountability), technological (development of information and communication technology, and role of virtual courses), economic (economic situation of the country, and movement toward third and fourth generation universities), political (role of policies, laws, regulations, rules and policymakers), and values (views of the community on the role of education, and views of the educational system on medical education discipline).

Conclusion: The most important key factors were student admission and recruitment policies, lack of accurate information on the follow up of graduates, the role of virtual courses and its opportunities and threats, lack of curriculum review and the need to move towards social accountability. This study was a preliminary step towards the foresight of the discipline; so, it is recommended that future studies develop scenarios (possible, feasible and desirable) for the future of the discipline.

Keywords: key factor, foresight, medical education discipline, STEPV model, qualitative study

\section{Introduction}

The continuous development of medicine requires the utilization of scientific potentials in other scientific and technological fields. The medical education discipline is one of the interdisciplinary fields that make contributions to the development of medical knowledge worldwide. Therefore, the worldwide interest in medical education and the need for this type of science provided the basis for its formation as a separate discipline. ${ }^{1,2}$
Correspondence: Nikoo Yamani Department of Medical Education, Medical Education Research Center, Isfahan University of Medical Sciences, Hezar Jerib Avenuo, PO Box 8I7467346I, Isfahan, Iran

Tel +989133089519

Email nikooyamani@gmail.com 
Medical education in the world is provided with different approaches. Some universities such as Dundee, Calgary, McMaster, Harvard, Karolinska and Maastricht offer it in the form of short- and long-term courses leading to both master's and Ph.D degrees. ${ }^{3,4}$

In Iran, medical education is in the form of a discipline with interdisciplinary nature in postgraduate studies (two years with a degree) and in both in-person and virtual as well as Ph.D (four and a half years with a degree) and in person. The matriculation exam in this discipline is in accordance with the regulations of the Ministry of Health and Medical Education. There are criteria for selecting students in the order of priority among groups such as faculty members of medical sciences universities and colleges across the country, faculty members of Islamic Azad University of Medical Sciences, masters (MSc) of medical sciences, holders of a doctorate in general medicine, pharmacy and dentistry, doctors of clinical specialties. The duration and structure of the course is based on the by-laws and conditions of the two master's and doctoral degrees approved by the Supreme Council for Planning of Medical Sciences. ${ }^{4,5}$

With the development of medical sciences, the discipline of medical education has also undergone various transformations. ${ }^{2}$ Ronald Harden, as a co-founder of the medical education, addressed in his book: "A Practical Guide for Medical Teachers" new horizons of medical education including globalization of healthcare delivery and the international dimensions of medical education, reconceptualization of the role of the doctors, changes in the context and structure of gaining clinical experience, continuous advancements on modern learning technologies and their impact on learning and teaching, transformations in the concept of assessment and its role in medical education, recognition of the professionalism and scholarship in medical education. ${ }^{1}$

Various reports, including the one by the Steering Committee of Medical Education Generalists highlighted trends and megatrends affecting the future of medical education. These ten megatrends include globalization, ${ }^{6}$ simulation, rising costs of medical care and medical education, redefining ideal physician traits and characteristics, the need for continuity and collaboration across the medical education timetable, interdisciplinary and interprofessional health care education, understanding medical education as part of health care enterprise, the need for lifelong learning and support for the medical profession, changes in medical education setting (from hospital to outpatient, office and community) and technology. ${ }^{7,8}$

During the last ten years, developments such as expanding medical disciplines and universities, and increasing admission of students and faculties have been observed in our country. These challenges represent the important position of the medical education discipline in maintaining and improving quality in line with the quantitative development of disciplines, colleges and universities of medical sciences. Therefore, policymaking is important for the development of medical education discipline. One of the challenges facing the medical education discipline is the diversity of the characteristics of entrants. This diversity and breadth of entry criteria raises concerns for policy makers about the discipline and its future. A look at motivations of candidates for choosing this discipline provides the relevant evidence. Sabouri Aghbulagh Rostam Khan et al examined students' motivations for studying in medical education discipline. Their reasons were the ease of entry compared to other disciplines, the absence of virtual education in the previously studied discipline, a way out of the clinical environment and others. ${ }^{9}$

In addition to the aforementioned developments, challenges and concerns, and rapid changes in various social, political, economic, technological, and environmental spheres also make the future of the health and medical education system more complex and risky. Understanding future uncertainties provide a good platform for medical education decision makers to gain information. ${ }^{10}$

One of the tools available for achieving the abovementioned goal is the use of foresight. Foresight is to describe a collection of strategies to identify changes and improve decision-making procedures. ${ }^{11}$ This study was conducted aiming at identifying key factors affecting the future of medical education discipline in 2025 based on STEPV model.

\section{Materials and Methods Research Design}

This study was a qualitative content analysis with a directed approach. The STEPV model has been used to identify and categorize key factors affecting the future of medical education discipline. Foresight studies use this model for structured analysis. This model provides a framework to help consider different variables. This type of classification provides assurance that the 
views are compatible with different aspects of reality. ${ }^{12}$

The social, technological, economic, political, and value-driving forces that shape the future of medical education discipline are examined on the basis of this model. ${ }^{13-16}$

\section{Research Paradigm}

The study was conducted within the constructivist research paradigm. In this paradigm, knowledge is socially constructed through the interaction of the researcher with the participants. In this paradigm, there are multiple realities, and each participant has a different view of it. ${ }^{17}$

\section{Participants}

The participants of this study included 31 teachers, students and graduates (master's degree, in-person and virtual) and Ph.D of medical education discipline. The participants were selected through purposive sampling with maximum diversity. The inclusion criteria for selecting teachers consisted of board discipline membership, full-time faculty member of the medical education department, teaching at least one of the specialized courses related to the discipline, and a minimum of 5 years of experience working with the medical education department. Each faculty member who had at least one of the mentioned criteria was included in the study. Inclusion criteria for selecting students and graduates consisted of faculty member in disciplines other than medical education, working for the Education Development Center (EDC) or the Education Development Office (EDO), executive responsibilities related to medical education, and unemployed students and doctoral students in medical education with or without a master's degree in medical education. Purposive sampling of 31 participants from 8 universities revealed differences in aspects and participants in this study. That number was enough to reach the thematic saturation.

\section{Spatial and Temporal Scope}

This study was carried out at the national level and at 8 universities of medical sciences with medical education departments (Tehran, Iran, Shahid Beheshti, Isfahan, Mashhad, Shiraz, Tabriz and Kerman) in 2018-2019. The reason for choosing these 8 universities was the existence of a medical education department within the organizational structure of the university.

\section{Researcher (Characteristics, Role, Reflexivity) \\ Researcher Characteristics}

The first author has medical education experience. She received her master's degree in medical education between 2011 and 2014. She has 9 years of experience in medical education and also 6 years of experience in qualitative research. Based on his experience, she considered challenges and concerns about the future of the field and its ambiguity and needed to consider the future of the field. Her hypothesis is based on personal experience (through interaction with teachers, students, and graduates) and review of relevant literature.

\section{Researcher's Role}

The researcher's role included setting research questions, selecting the participants, specifying the research paradigm and approach and method of study, coding and data analysis process, and determining the validity process.

\section{Reflexivity}

In order to reflect the reflexivity in the research and to make sure that the researcher has a meaningful and reliable reflection of the research participants and not the researcher herself, the researcher tried to immerse herself in her research at every step. She was known to the research participants before starting the study. "Knowing" (from her own background) was helpful in what the participants said about medical education (and in terms of identifying important issues). However, as a researcher, she made no conscious effort to accept the common assumptions. In addition, reflectivity was achieved by the research team through analysis and writing along with recording, discussing and challenging assumptions and she retained her reflective memories.

\section{Ethical Considerations}

This study is part of a Ph.D dissertation at Isfahan University of Medical Sciences with the code of ethics no: IR.MUI.MED.REC.1397.179. An informed consent form was obtained from the participants prior to the interview. To protect the privacy of the participants, all interviews were conducted and analyzed by the interviewer herself using a proprietary code for each individual. The participants were assured that they could refuse to participate or withdraw from study at any time. 


\section{Data Collection and Analysis}

Data collection was conducted using 31 in-depth semistructured individual interviews and by the first author (AF). The time and place of the interviews (setting) were determined by the participants themselves. Interviews were conducted by "face-to-face" and "by-phone" methods (23 face-to-face and 8 by-phone interviews). The researcher conducted and recorded the interview after introducing herself and explaining the purpose of the study and obtaining informed consent. Each interview lasted 45 to 60 mins since the target group of the interview was diversified, in an interview with the teachers, they were first asked to give a brief history of the discipline and their related experiences. The question was then asked as to what trends and events have been going on in the discipline of medical education since its emergence. The first question for students and graduates was: "What were the reasons for choosing medical education as your discipline of study?" The following questions (probing) were asked according to the answers to the previous questions, specifically: "Which key factors do you think may have an impact on the future of medical education discipline in the next eight years?" Other questions were guided by the STEPV model classes. The new participants were interviewed until data saturation was achieved; in other words, the interviews continued until no additional themes related to the study goals emerged. Interviews were then transcribed (word by word) and analyzed using Maxqda 10 software and directed content analysis.

\section{Trustworthiness}

To ensure the validity and accuracy of the data, the Lincoln and Guba criteria (four components of credibility, dependability, transferability, and confirmability) were used. ${ }^{18}$ To establish credibility of data, peer debriefing was used. For this purpose, the codes extracted were provided to two colleagues and based on their views, some changes were made to the data. It was also attempted to increase the credibility of the data by maximizing the diversity of participants in terms of education level, gender, faculty member/non-member and employed/unemployed. For data dependability, one person with experience in qualitative research, medical education and foresight examined the classification of data. Regarding transferability, it was also attempted to accurately record and describe all the steps of the methodology in detail. To establish confirmability, an external observer with experience in qualitative research verified and validated all study processes from implementation to analysis of findings.

\section{Results}

There were 31 participants in this study including 13 teachers (10 board members and 3 non-board members), 11 students, and 7 graduates. Interviewees included 12 men and 19 women. The average age of the participants was 46 years, ranging from 29 to 68 years. After analyzing the data, a total of 1260 initial codes were obtained. After removal of the repetitious codes and merging similar and overlapping ones, 616 codes were extracted. Finally, the data were subdivided into five main categories that included several subcategories (Table 1).

\section{Categories and Subcategories Obtained from Data Analysis and Classification Based on STEPV Model}

The following describes each of these subcategories:

\section{Social}

In the viewpoint of the participants, the characteristics of entrants into the discipline, motivations of candidates for entry into the discipline, national and international communications and interactions, the status of medical education

Table I Categories and Subcategories Obtained from Data Analysis

\begin{tabular}{|c|c|}
\hline Categories & Subcategories \\
\hline Social & $\begin{array}{l}\text { Characteristics of entrants into the discipline } \\
\text { Motivations of candidates for entry into the discipline } \\
\text { National and international communications and } \\
\text { interactions } \\
\text { Status of medical education within the academic } \\
\text { community } \\
\text { Movement toward social accountability }\end{array}$ \\
\hline Technological & $\begin{array}{l}\text { Development of information and communication } \\
\text { technology (ICT) } \\
\text { Role of virtual courses }\end{array}$ \\
\hline Economic & $\begin{array}{l}\text { Economic situation of the country } \\
\text { Movement toward third and fourth generation } \\
\text { universities }\end{array}$ \\
\hline Political & $\begin{array}{l}\text { Role of policies, laws, regulations and rules } \\
\text { Role of the policymakers }\end{array}$ \\
\hline Value & $\begin{array}{l}\text { Views of the community on the role of education } \\
\text { Views of the educational system on medical } \\
\text { education discipline }\end{array}$ \\
\hline
\end{tabular}

Abbreviations: STEPV, Social, Technological, Economic, Political, Value; EDC, Education Development Center; EDO, Education Development office; ICT, Information and Communication Technology; CHEMA, The Council of Higher Education Management Associations. 
within the academic community, and the movement toward social accountability were the key social factors that can influence the future of medical education discipline.

\section{Characteristics of Entrants into the Discipline}

From the perspective of the participants, in the future, the characteristics of the candidates, such as age and employment status, should be considered.

We were almost all in the same age group at the postgraduate level. But during the doctorate course, unfortunately we were very different in terms of age. Our perspectives, interests, and priorities were very different. One was thinking about going on a mission to resolve his service training course, another one was thinking to secure a future job. [P1.Student]

In my opinion, the discipline doesn't have much of a job and most people come into the discipline whose job is already characterized. [P28.Teacher]

\section{Motivations of Candidates for Entry into the Discipline}

The participants believed that candidates who choose this discipline may have a variety of motivations and reasons. These reasons and motivations can affect the quality of the output of the discipline and its future. These motivations included occupational needs, the role of previous education levels, ease of access, newness and applicability of the discipline, interest, the role of peers and facing educational problems and escaping the clinical environment.

I wondered whether to study in my own discipline; that is, the medical informatics, which I loved or medical education discipline. Then because my project hasn't been settled yet and I had little time till the postgraduate entrance exam, 2 or 3 months, and that I had to study very much harder for medical informatics to be accepted, I decided to choose medical education discipline. [P9.Student]

The person who seems to be a nurse or midwife who doesn't like night shifts and doesn't like treatment has a tendency to get into this discipline. [P18.Teacher]

\section{National and International Communications and Interactions}

In this subcategory were included the role of conferences, associations and specialized scientific assemblies, interdisciplinary and interuniversity teamwork, international communications, inter-sectoral interactions and generational gap.

The medical education discipline and AMEE conferences have very important roles because we could share our educational materials and experiences. [P30.Graduate]

Unfortunately, in medical education discipline, international communication and student exchange with other universities are too little that might be due to the newness of our discipline. [P14.Teacher]

\section{Status of Medical Education Within the Academic Community}

Medical education is a new and emerging discipline; so, the participants believed that the understanding of academic community of the discipline should be considered more in the future.

The scientific approach to medical education is not proper at some universities. Those who comment on the discipline may not have enough knowledge of it and that would hurt the body of the discipline. [P2.Student]

I think the most important thing is the position that this discipline has amongst other disciplines, whether it is recognized as a very well-honored one or not. [P24. Teacher]

\section{Movement Toward Social Accountability}

Social accountability is one of the important missions of medical sciences universities, and training of competent and responsible graduates who are responsive to the needs of society is one of the factors influencing quality of the discipline in the future.

What we expect from the graduate is the service he or she provides for the society. One of the goals of the health system is to respond to the needs of the community. [P10. Teacher]

Accountability is a very important issue in addition to research and treatment in education. For example, how can I be accountable to my students if my training is effective? [P19.Graduate]

\section{Technological}

Increasing improvements in technology were among other factors that the participants believed could influence the 
future of the discipline. In this regard, the participants noted the development of ICT and the role of virtual courses.

\section{Development of ICT}

According to the participants, the development of technology has changed the teaching and learning methods, and this increases the responsibilities of the graduates of the discipline in the future.

I think that virtual education will play a bigger role in the future, for example, the integration of technology in education. [P20.Graduate]

In future, we will not have these classes where the student is sitting in the classroom. We'll have discussions like telemedicine; we have to direct our training to that end. [P10.Teacher]

\section{Role of Virtual Courses}

The participants differed in their opinions on the quantity and quality of virtual courses. They referred to the student acceptance capacity of these courses, the criteria for entry and selection of candidates, the competencies of graduates, quality of teaching and learning methods, and acceptance methods for these courses.

Lots of students were admitted in virtual courses, with which I didn't agree. For example, some universities such as X University have around 200-300 students in virtual courses. I think these courses do not have the necessary competencies and are not as effective as the inperson courses. [P11.Teacher]

The great goodness of our discipline is practicality and can bridge the gap between theory and practice, but it did not happen to the virtual courses. [P25.Graduate]

\section{Economic}

Another factor considered by the participants as influencing the future of the discipline was economic. The participants noted the country's economic situation and the movement toward third and fourth generation universities.

\section{Economic Situations of the Country}

The economic crisis in the country is among the concerns that may influence the future of all disciplines of the medical sciences, including the medical education discipline.
Considering the economical problems in the country, these issues seem to be going to fade. That's because internal travels cost a lot, let alone the overseas trips with no governmental assistance. [P19.Graduate]

The utilizing Sabbatical Leave because of currency and budget problems is usually not very voluntary. [P24.Teacher]

\section{Moving Toward Third and Fourth Generation Universities}

The participants believe that generational transitions in universities can influence the future of academic disciplines, including medical education.

The paradigm of the universities has now changed and transformations are being made. In this paradigm shift, we have no choice but to make our universities such that they perform their researches at the edge of the knowledge and make it commercial successfully; this could be the key role of medical education. [P27.Graduate]

We are now confronted with the approach of the third and fourth generation universities, so our policy needs to discuss issues such as infrastructure development, proper human resources training, cost forecasting, education economics and so on. [P10.Teacher]

\section{Political}

The participants believed that policies, laws, regulations and rules, and policymakers may influence the future of the discipline.

\section{Role of Policies, Laws, Regulations and Rules}

The participants believed that student admission policies, policies for taking up graduates, and other government policies and programs, including educational system development plans and transformation packages, can play an important role in the future of the discipline.

I think that the laws and policies applied at the ministry level are very effective, for example three years ago, discussions were made on the university $\mathrm{X}$ with 1300 students; or that, they are going to enter around 100 physicians to Ph.D. That would decrease the motivation and attitude. [P20.Graduate]

In the three first periods with WHO, we only accepted the faculty members. In the next periods, they were postgraduate and then, graduate. The most important task of 
a profession is entry control. Actually, we were loose in entry control. [P29.Teacher]

\section{Role of Policymakers}

The participants believe that policymakers, board members and the quality of their decisions and performance can play an important role in the future of the discipline.

Our board members have far more responsibilities than you. It's not that I am a very educated person and so I am a board member and can make decisions for the future. [P12.Teacher]

High-level policy change requires that the primary focus be on the necessity of the orient, starting from the first step and moving to the lower ranks. [P6.Student]

\section{Values}

In this category, the participants pointed to the views of the community on the role of education in general and the views of the educational system toward the discipline of medical education.

\section{Views of the Community on the Role of Education}

In this regard, the participants discussed the attitudes of credentialism, physician dominance, and prioritizing treatment over education.

In disciplines that are theoretical, they attend a number of classes and then pass a test and it's over, but in medical education discipline, it's not all about getting the degree. [P5.Student]

The motivations of earlier generations of medical education are different from those of the new generation. The incentives are more materialistic now, so many people want to go to college and get a degree. [P16.Teacher]

\section{Views of Educational System Towards Medical Education Discipline}

According to the participants, because the medical education is a new and emerging discipline, there is still insufficient knowledge and attitude in the community toward this discipline.

Many plans of education are never accomplished. That's because education is not important at all here. Chancellor, the vice chancellor of education and the dean of the medical school should have an open mind. [P8.Student]

Managers' view of the field is very important. Perhaps one of the reasons for allowing these disciplines to continue is to discontinue the positive outlook they have. [P11. Teacher]

\section{Discussion}

As with other disciplines, medical education is exposed to developments that shape the future of this discipline on a continuous basis. Some of these developments are of national and local origin, and others of global and international origin.

Among the social factors that influence the future of the discipline are the age and employment status referred to by the participants. The results of a study by The Council of Higher Education Management Associations (CHEMA), aimed at identifying the driving forces that influence the future of higher education in the US and Canada over the next 10 years, also addressed the changing demographic characteristics of students. ${ }^{19}$ Some of our participants believed that unemployed students had a higher quality education period than employed ones. The results of the study by Mohamadian et al confirm this finding. ${ }^{20}$ But Hakkinen believes that working while studying will complement formal education, responsibility and greater familiarity with the world of employment. ${ }^{21}$

According to the participants, the study of the motivations of the candidates could also influence the future of medical education discipline. Chapman also considers many factors influencing the choice of discipline and the university such as interest, level of personal aspirations, attitudes, academic performance and competencies, family and friends and university characteristics and so on. ${ }^{22}$

Due to its interdisciplinary nature, the discipline of medical education needs to strengthen communications and interactions with other disciplines of medical sciences. The results of the study on the future of medical education in Canada, with the aim of meeting current and future needs of the society in terms of health, identified 10 key strategies for the future of medical education. One of these 10 strategies was "focusing on interdisciplinary skills". ${ }^{23}$

The congresses, conferences, seminars, and other specialized science communities, despite their high costs, and advantages and disadvantages can play an important role in changing views of the individuals on the role and importance of medical education discipline. According to 
Sundeep, medical education conferences should play a vital role in continuing education and developing the skills of their stakeholders. But today, because of these congresses with a large number of individuals and lack of respect for some of the important aspects, they are not adequate enough. $^{24}$

Another important issue mentioned by the participants and especially the teachers of the discipline was the generation gap between the students and the teachers. The results of a study by Alkatan on the effect of factors related to the preceptor and generation gap on education in the residency period showed that from among the three categories of factors related to preceptor qualifications and skills, the most important ones were behavioral patterns and generation gap. ${ }^{25}$

The knowledge and understanding of the academic community about medical education discipline was among other important social factors. EDCs, EDOs and medical education departments of universities can play an important role in the development of the discipline. Baume and Kahn identified eight items among the activities of EDCs, one of which is to provide incentives to staff and promote rewarding policies for learning and teaching and development of education. ${ }^{26}$

The graduate community of medical education discipline also plays an important role in raising awareness and attitudes towards the discipline in the future. Craft considers that having graduates who are highly knowledgeable, have a positive attitude, and are especially skillful and creative is among the concerns of the educational system. He believes that nurturing creative thinking is one of the ultimate goals of any educational system. ${ }^{27}$

Social accountability is another issue that plays an important role in the future of the discipline. The curriculum of the disciplines must be responsive to the needs of the community. Various studies have been conducted on the lack of responsiveness of educational curricula and their inability to train competent graduates. Among them is the study examining the skills of graduated physicians in the United Kingdom, in which only $4 \%$ of graduates agreed with the appropriateness of the curricula to make competent physicians and a large percentage (40\%) disagreed. ${ }^{28-30}$

Today, the growth and development of information and communication technologies and virtual education is such that the impact of technological factors on the future of academic disciplines, and in particular medical education, cannot be ignored. De Boer et al examined the trends that influence the future of higher education and universities. One of these trends has been the development of ICT. ${ }^{31}$

The role of virtual courses can be discussed from two perspectives; first, the role of virtual education in all disciplines of medical sciences and second, the provision of virtual courses in medical education discipline. The first perspective could affect the overall process of teaching and learning and the methods of evaluation of the disciplines. The second perspective raises concerns about the quantity, quality and competence of its graduates. Otto Peters likens the teaching process of the distance learning system to industry and industrial products and calls it the teaching learning industrialization theory. He believes that as we pursue mass production in the industry, we also seek to recruit and graduate large numbers of learners in distance education. ${ }^{32}$

Moreover, the economic situation of the country was one of the economic factors considered by the participants. Crises such as the sanctions have reduced the use of Sabbatical Leave and international communications across all disciplines, including medical education. VincentLancrin examined trends affecting higher education. These trends included economic issues, financing, and the importance of the market and its sovereignty. ${ }^{33}$

Moving toward third and fourth generation universities is one of the new concerns for all managers, policymakers, planners and the academic community. According to the European Union report, entrepreneurship is not yet integrated into curriculum and educational institutions and universities. Therefore, it is necessary to use interactive learning and teaching methods based on experience and multidisciplinary collaboration in the training of skilled and entrepreneurial individuals. ${ }^{34}$

Another important factor in the future of medical education discipline is political factors. Student admission policies are among the influential political factors. The participants believed that no estimates of the number of students and graduates and their job status are available. According to Al-Sawai et al, workforce planning is considered as one of the important roles of health planners. ${ }^{35}$

Policymakers also play a vital role in determining laws, policies, and changing attitudes toward the discipline. The lack of a private labor market is one of the concerns of graduates for the future of discipline. Walter and Craig believe that universities play a key role in resolving the problems of labor market and industry. They can make the students more competent by making changes to curricula and adding practical courses. ${ }^{36}$ 
The role of high-level documents and plans for the evolution of the education system and their impact on the future of the discipline should not be overlooked. Chin et al considered the roadmap as the most useful tool for organizations, policymakers, and researchers to deliver high-quality services. ${ }^{37}$ In our study, the necessity for a coherent roadmap to clear the path to the future of the discipline is also considered essential.

The values and norms of society can directly and indirectly influence the various processes and their future. One view in this regard is credentialism, which is especially observed in virtual courses. The participants believed that the majority of graduates of virtual courses do not have the necessary competencies after graduation. Dikici et al investigated the factors influencing the choice of specialty discipline among first-year medical students in Turkey. The findings of this study showed that obtaining higher degrees to achieve higher income and better job positions were among the important factors for choosing a specialty discipline. ${ }^{38}$

Prioritizing treatment and research over education is among other concerns with the future of the discipline. One of the reasons for the decrease of education's priority is the materialism, which is effective not only in treatment, but also in student admissions. An example can be found in virtual medical education courses. Kendrick considered that the costs of virtual education included the costs of producing educational content, teaching the faculty, evaluation, and other necessary costs. ${ }^{39}$ On the other hand, virtual courses may have a positive impact and even lead to lower educational costs. The results of a study at the University of Illinois showed that the cost of education had decreased when e-learning had replaced in-person education. ${ }^{40}$

The role of university administrators and officials and their attitude toward medical education discipline can have a significant impact on improving the quality of the discipline in the future. Khalid et al believe that the administrators' support for education can lead to a favorable environment in the organization. The administrator of the organization creates a positive organizational environment that motivates learners and educators to learn. ${ }^{41}$

\section{Limitations of the Study}

We had four limitations in this study. One of the limitations of this study was the large number of universities and the variety of study target groups. This limitation made it difficult to hold in-person meetings of brainstorming, and especially focus groups and expert panels. For this reason, the researcher used individual interviews. These constraints limited the ability to challenge stakeholder views, generate debate among individuals and critique reviews, and explore differences and similarities of views. The second limitation was the busy schedules of the teachers to coordinate the time and place of the interview. The third limitation was lack of quantitative information. Certainly, this information could enrich the data of this study. Finally, the fourth limitation of this study was the lack of member check. This can compromise the accuracy of the study and the validity of the data. To control this limitation, we used other methods such as peer debriefing, maximizing the diversity of the participants, accurately recording and describing all the steps of the methodology and using an external observer to achieve accuracy.

\section{Conclusion}

Based on the findings of this study, a variety of key factors could influence the future of medical education discipline. Meanwhile, there are differences in the contribution of some of these factors and their impact on the future of the discipline. Some of the most important key factors are student admission and recruitment policies, lack of accurate information on the follow up of graduates, the role of virtual courses in the discipline and its opportunities and threats, lack of curriculum review and the need to move towards social accountability. These factors make the responsibility of policymakers, planners and managers more serious for future planning. This study is a preliminary step towards the foresight of the discipline; so, it is recommended that future studies develop scenarios (possible, feasible and desirable) for the future of the discipline.

\section{Data Sharing Statement}

The datasets used and/or analyzed during the current study are available from the corresponding author on reasonable request.

\section{Acknowledgments}

We are grateful to all members of the board of medical education, medical education departments of universities of medical sciences of Tehran, Iran, Shahid Beheshti, Isfahan, Mashhad, Shiraz, Tabriz and Kerman, their teachers and all students and graduates who cooperated with us. This study was funded by Medical Education Research Center of Isfahan University of Medical Sciences with the 
approved code 397468 and National Agency for Strategic Research in Medical Education, Tehran, Iran Grant No 970006.

\section{Author Contributions}

All authors contributed to data analysis, drafting and revising the article, gave final approval of the version to be published, and agreed to be accountable for all aspects of the work.

\section{Disclosure}

The authors report no conflicts of interest in this work.

\section{References}

1. Dent JA, Harden RM. A Practical Guide for Medical Teachers. 4th ed. Cherchil Livingston: Elsevier; 2013.

2. Amin Z, Hoon Eng KH. Basics in Medical Education. National University of Singapore: World Scientific Publishing Co. Pte. Ltd; 2007.

3. MedEdWorld, a global medical education community. Available from: https://www.mededworld.org. Accessed February 25, 2020.

4. Karimi Moonaghi H, Montazeri R. A comparative study of the curriculum of master's degree in medical education in Iran and some other countries. Dev Med Educ. 2014;11(4):e59743.

5. Education DM for. Manual Guide for Admitting Undergraduate Students; 2019. Ministry of Health and Medical Education. Available from: http://www.sanjeshp.ir/PDF.aspx?newsid= 50897\&type=application/pdf. Accessed February 25, 2020.

6. Karle H. International trends in medical education: diversification contra convergence. Med Teach. 2004;26(3):205-206. doi:10.1080/ 01421590410001667418

7. Lazarus CJ. 10 megatrends in medical education. Oncol Times. 2009;31(1):6-9. doi:10.1097/01.COT.0000343989.66641.c3

8. Nabipour I. Megatrend analysis of the health policies of Iran. ISMJ. 2014;17(5):1007-1030.

9. Aghbulagh Rostam Khan T, Imanipour M, Ahmadi S. Reasons and motives for selecting major of medical education as postgraduate course: a qualitative study. The Journal of Medical Education and Development. 2017;12(3):133-146

10. Tabatabai S, Ziaee AM. Trends in postgraduate medical education in Iran. BMC Heal Serv Res. 2014;14(Suppl 2):124. doi:10.1186/14726963-14-S2-P124

11. Loveridge D. Foresight, the Art and Science of Anticipating the Future. 1st ed. Routledge; 2008.

12. Van der Heijden K, Bradfield R, Burt G, Cairns G, Wright G. The Sixth Sense: Accelerating Organizational Learning with Scenarios. John Wiley \& Sons; 2002.

13. Foresight. The Manual, GCPSE (Global Centre for Public Service Excellence). UNDP; 2014.

14. Van Duijne F, Bishop P. Introduction to strategic foresight. 2018. Available from: https://www.achieveengagement.org/pdfs/strategicforesight-primer.pdf. Accessed February 25, 2020.

15. Pillkahn U. Using Trends and Scenarios as Tools for Strategy Development. Shaping the Future of Your Enterprise. Erlangen: Publicis Corporate Publishing; 2008.

16. European Foresight Platform (EFP). Available from: http://www.fore sight-platform.eu. Accessed February 25, 2020.

17. Bunniss S, Kelly DR. Research paradigms in medical education research. Med Educ. 2010;44(4):358-366. doi:10.1111/j.13652923.2009.03611.x
18. Lincoln YS. Emerging criteria for quality in qualitative and interpretive research. Qual Inq. 1995;1(3):275-289. doi:10.1177/ 107780049500100301

19. Goldstein PJ. The future of higher education: a view from CHEMA; 2006. Available from: http://www.chemanet.org. Accessed February 25,2020 .

20. Mohamadian Z, Fallah S, Safdarian A, Jalali Z. The relationship between educational achievement and employment status of graduate students in the College of Management and Accounting of Shahid Beheshti University. Indian J Fundam Appl Life Sci. 2015;5 (S1):1262-1270.

21. Hakkinen L. Working while enrolled in a university: does it pay? Labour Econ. 2006;13(2):167-189. doi:10.1016/j.labeco.2004.10.003

22. DeRonck NG. The Impact of Family Structure and Involvement on the College Enrollment of Potential First Generation College Students. Central Connecticut State University New Britain, Connecticut; 2007.

23. Association of Faculties of Medicine of Canada. The Future of Medical Education in Canada (FMEC): A Collective Vision for MD Education. Association of Faculties of Medicine of Canada; 2010.

24. Mishra S. Do Medical Conferences Have a Role to Play? Sharpen the saw; 2016.

25. Alkatan HM. Impact of trainers-related factors and "Generation gap" on the quality of local residency training. Int J Curr Res. 2015;7 (12):24221-24224.

26. Baume D, Kahn P. How shall we enhance staff and educational development? Enhancing Staff Educ Dev. 2004. doi:10.4324/ 9780203416228

27. Craft A. Creativity in Schools: Tensions and Dilemmas. Abingdon: Routledge; 2005. Available from: http://oro.open.ac.uk/id/eprint/ 23285. Accessed February 25, 2020.

28. Goodfellow P, Claydon P. Students sitting medical finals-ready to be house officers? J R Soc Med. 2001;94(10):516-520. doi:10.1177/ 014107680109401007

29. Burch V, Nash R, Zabow T, et al. A structured assessment of newly qualified medical graduates. Med Educ. 2005;39(7):723-731. doi:10.1111/med.2005.39.issue-7

30. Moercke AM, Eika B. What are the clinical skills levels of newly graduated physicians? Self-assessment study of an intended curriculum identified by a Delphi process. Med Educ. 2002;36(5):472-478. doi:10.1046/j.1365-2923.2002.01208.x

31. De Boer H, Huisman J, Klemperer A, et al. Academia in the 21st Century: An Analysis of Trends and Perspectives in Higher Education and Research. Adviesraad voor het Wetenschaps-en Technologie-beleid; 2002.

32. Peters O. Distance Education in Transition, Developments and Issues. 5th ed. BIS-Verlag der Carl-von-Ossietzky-Univ.; 2010. Available from: https://books.google.com/books?id= k3oHYAAACAAJ. Accessed February 25, 2020.

33. Vincent-Lancrin S. Building futures scenarios for universities and higher education: an international approach. Policy Futur Educ. 2004;2(2):245-263. doi:10.2304/pfie.2004.2.2.3

34. DG E. Final Report of the Expert Group: Entrepreneurship in Higher Education, Especially within Non-Business Studies; 2008. Available from: https://ec.europa.eu/growth/content/final-report-expert-groupentrepreneurship-higher-education-especially-within-non-business-0_ en. Accessed February 25, 2020.

35. Al-Sawai A, Al-Shishtawy MM. Health workforce planning: an overview and suggested approach in Oman. SQU Med J. 2015;15(1):27-33.

36. Walter O, Craig III. Preparing the engineering technology graduate for the global marketplace. Proc 2008 IAJC-IJME Int Conf. 2008. Available from: http://ijme.us/. Accessed February 25, 2020.

37. Chin MH, Clarke AR, Nocon RS, et al. A roadmap and best practices for organizations to reduce racial and ethnic disparities in health care. $J$ Gen Intern Med. 2012;27(8):992-1000. doi:10.1007/s11606-0122082-9 
38. Dikici FM, Yaris F, Topsever P, et al. Factors affecting choice of specialty among first-year medical students of four universities in different regions of Turkey. Croat Med J. 2008;49(3):415-420. doi: $10.3325 / \mathrm{cmj} .2008 .3 .415$

39. Kendrick D. The cost effectiveness of component in webbased instructional system: a cost benefit analysis of e-learning course redesign for the distance learning environment. Doctoral Dissertation. Coll Grad Stud; 2006.
40. Rumble G. The costs and costing of networked learning. J Asynchronous Learn Networks. 2001;5(2):75-96.

41. Khalid MM, Ashraf M, Yousaf U, Rehman CA. Assessing impact of management support on perceived managerial training effectiveness in public organizations of Pakistan. Eur J Soc Sci. 2011;22:1.

\section{Publish your work in this journal}

Advances in Medical Education and Practice is an international, peerreviewed, open access journal that aims to present and publish research on Medical Education covering medical, dental, nursing and allied health care professional education. The journal covers undergraduate education, postgraduate training and continuing medical education including emerging trends and innovative models linking education, research, and health care services. The manuscript management system is completely online and includes a very quick and fair peer-review system. Visit http://www.dovepress.com/testimonials.php to read real quotes from published authors. 